\title{
A Case of Facial Lipoatrophy Secondary to Lupus Profundus Managed with Lipofilling Technique
}

\author{
Luigi Valdatta, Mario Cherubino, Federico Tamborini, \\ Igor Pellegatta, and Francesca Maggiulli
}

U.O. di Chirurgia Plastica e Ricostruttiva, Ospedale di Circolo e Fondazione Macchi, Università degli Studi dell'Insubria, Viale Borri 57, 21100 Varese, Italy

Correspondence should be addressed to Igor Pellegatta, igor.pellegatta@me.com

Received 27 September 2012; Accepted 12 November 2012

Academic Editors: S. A. Cuevas-Covarrubias, M. Jinnin, J. A. Tschen, and S. Uzun

Copyright () 2012 Luigi Valdatta et al. This is an open access article distributed under the Creative Commons Attribution License, which permits unrestricted use, distribution, and reproduction in any medium, provided the original work is properly cited.

Facial lipoatrophy is one of the most difficult complication in the patients with lupus profundus. In this paper, we present a case of a 55-year-old woman affected by lupus profundus, with a grade V lipoatrophy, treated with lipofilling technique. No complications were observed and results at 12 months were stable, natural, and symmetric.

\section{Introduction}

Lupus profundus [1-6] is a clinical condition characterized by subcutaneous nodular lesions localized at the face, arms, legs, trunk, and abdominal region (see Figure 1). Lipoatrophy follows the nodular stage after its resolution. Lupus profundus incidence is between $1 \%$ and $3 \%$ in patient with LES. Autoimmunitary etiology is confirmed by low complement levels and presence of antinucleus antibody. Manifold complications are possible in lupus profundus: lipoatrophy, alopecia [7], enophthalmos [8,9], central retinal artery occlusion [10], mastitis [11], thrombophlebitis [12], and proptosis [13]. Despite its benignity, lipoatrophy is psychologically important in everyday life. Facial lipoatrophy can be considered following a grading scale [14] from first to fifth grade. Different strategies were proposed in order to solve this situation: nonabsorbable fillers such as polymethylacrylate [15] do not give striking results, and complications [16], as granulomatous "rubberizing" reaction, are rare but possible. Free flaps, especially anterolateral thigh flap [17] and temporal flap [18], are rarely used giving the difficulty of the surgical procedure and the unnatural results. Yoshimura's CAL technique [19] is a valid and quite stable option but requires adipose-derived stem cells extraction in laboratory, 7-10 days for cell culture, and a double step surgical procedure (fat extraction and fat injection). Authors report their experience regarding a case of patient with Lupus Profundus treated with lipofilling technique [20-22].

\section{Matherials and Methods}

A 55-year-old patient suffering from lupus panniculitis, treated with hydroxychloroquine, methotrexate, and metilprednisone, showed clinical signs of lipoatrophy in facial, abdominal, and mammary areas. Patient was submitted to three surgical procedures of lipofilling with Coleman's technique [23] at 6-month distance among every step. First adipose graft was $12 \mathrm{cc}$, second $15 \mathrm{cc}$, and third $18 \mathrm{cc}$, picked from abdominal fat. Submalar, parotideal, perioral, and mandibular sites was grafted with adipose tissue, using 9 French microcannules. Only one hole for each side of the face was necessary to introduce the graft. Every procedure was performed in outpatient surgery and in local anesthesia with sedation.

\section{Results}

No complications due to infections or surgical technique were observed after each procedure. A mild intolerance to the antibiotic therapy was easily solved. 12-month evaluation after third reconstructive step showed the stability 


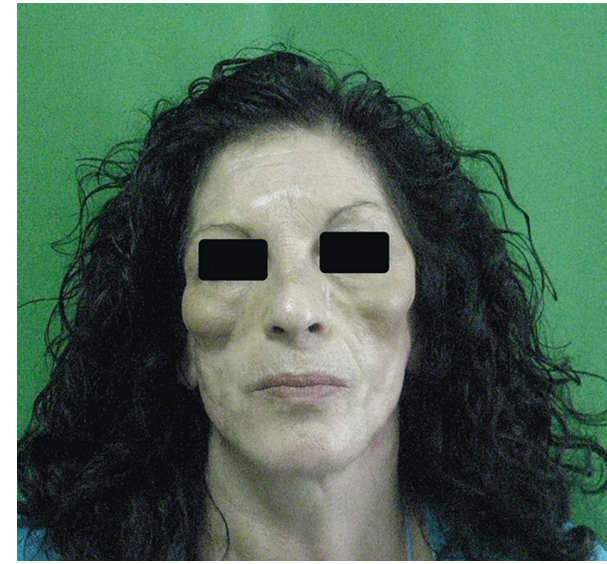

Figure 1: Initial condition of the patient.

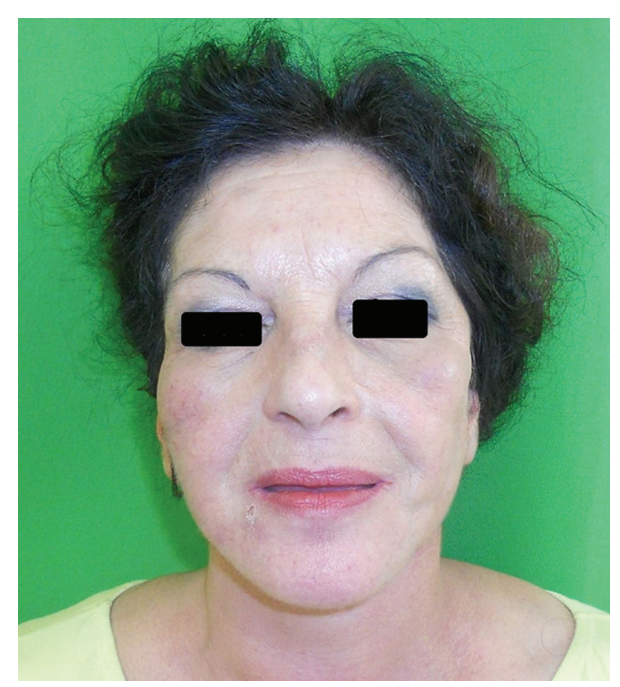

FIGURE 2: Final result after three lipofilling procedures at 12-month followup.

of the result and the emptiness localized in the submalar and parotideal region was totally filled (see Figure 2). Also the aspect of typical cutaneous lesions of lupus syndrome was improved. The first of three grafts did not supply an acceptable result as because of copious smoking by the patient during immediate postoperatively period. Final result was natural and symmetric.

\section{Discussion}

Facial lipoatrophy is an important issue for the aesthetic acceptance of a patient affected by lupus profundus. In our case a triple lipofilling procedure has given stable results at 12-month followup. Longer followup would be necessary to prove the persistence of the results.

Despite its rarity, severe complications of lipofilling in the treatment of facial lipoatrophy are reported [24]. The impairment of facial nerve may represent one of the problems due to surgical technique.
Fat grafting should be examined as option in management of three-dimensional defects of facial lipoatrophy: the minimal invasivity, the simplicity of the surgical procedure, the fast convalescence, and the possibility of modulating the quantity of the graft are the main benefits of this option.

In our experience one of the most essential factors in the persistence of the graft was patient's smoking habit. We believe that absolute abstinence in smoking in the months after the surgery would have dramatically improved the final results and decreased the number of procedures needed. Moreover, we repute that, as demonstrated in breast augmentation [25], new automated devices extracting adipose stem cells would improve the graft persistence.

\section{Conclusions}

Lupic panniculitis is a relatively rare condition that causes facial lipoatrophy. Different strategies were adopted in order to fill the soft tissue defect. Nonabsorbable filler and free flaps are two of the options available. The management of the above-mentioned case provided good results. No complications were observed and the period of healing was minimal. Photographic evaluation demonstrates the persistence of adipose tissue and patient satisfaction degree was excellent. Hence, we believe that lipofilling would represent a simple, cheap, and fast method to face an important complication of lupus profundus, as facial lipoatrophy.

\section{References}

[1] K. Aggarwal, V. K. Jain, and S. Dayal, "Lupus erythematosus profundus," Indian Journal of Dermatology, Venereology and Leprology, vol. 68, no. 6, pp. 352-353, 2002.

[2] S. Arai and K. Katsuoka, "Clinical entity of Lupus erythematosus panniculitis/lupus erythematosus profundus," Autoimmunity Reviews, vol. 8, no. 6, pp. 449-452, 2009.

[3] A. N. Crowson and C. Magro, "The cutaneous pathology of lupus erythematosus: a review," Journal of Cutaneous Pathology, vol. 28, no. 1, pp. 1-23, 2001.

[4] N. Khalfallah, S. Azzabi, L. Ben Hassine et al., "Cutaneous lupus profundus," La Tunisie Medicale, vol. 81, no. 2, pp. 134139, 2003.

[5] T. N. Rao, K. Ahmed, and K. Venkatachalam, "Lupus erythematosus profundus," Indian Journal of Dermatology, Venereology and Leprology, vol. 76, no. 4, p. 448, 2010.

[6] B. E. Strober, "Lupus panniculitis (lupus profundus)," Dermatology Online Journal, vol. 7, no. 2, p. 20, 2001.

[7] C. H. Rhee, S. M. Kim, M. H. Kim, Y. W. Cinn, and C. W. Ihm, "Two cases of linear alopecia on the occipital scalp," Annals of Dermatology, vol. 21, no. 2, pp. 159-163, 2009.

[8] T. Y. Kao, M. K. Yoon, T. J. McCulley, B. S. Ruben, and T. N. Hwang, "Acquired enophthalmos in lupus erythematosus profundus," Journal of Neuro-Ophthalmology, vol. 30, no. 1, pp. 64-66, 2010.

[9] V. Wiwanitkit, "Lupus erythematosus profundus and enophthalmos," Journal of Neuro-Ophthalmology, vol. 31, no. 2, p. 195, 2011.

[10] P. Sudhakar, G. V. Shah, F. Saponara, D. R. Fullen, and J. D. Trobe, "Central retinal artery occlusion secondary to orbital inflammation in lupus erythematosus profundus," Journal of Neuro-Ophthalmology, vol. 32, no. 1, pp. 93-94, 2012. 
[11] C. Kinonen, P. Gattuso, and V. B. Reddy, "Lupus mastitis: an uncommon complication of systemic or discoid lupus," The American Journal of Surgical Pathology, vol. 34, no. 6, pp. 901906, 2010.

[12] M. Yeung, W. S. Wood, C. Grondin, and A. Chalmers, "Lupus profundus presenting as thrombophlebitis," Journal of Rheumatology, vol. 16, no. 10, p. 1400, 1989.

[13] K. L. Magee, S. R. Hymes, R. P. Rapini, J. W. Yeakley, and R. E. Jordon, "Lupus erythematosus profundus with periorbital swelling and proptosis," Journal of the American Academy of Dermatology, vol. 24, no. 2, part 1, pp. 288-290, 1991.

[14] B. Ascher, S. Coleman, T. Alster et al., "Full scope of effect of facial lipoatrophy: a framework of disease understanding," Dermatologic Surgery, vol. 32, no. 8, pp. 1058-1069, 2006.

[15] I. M. Carvalho Costa, C. P. Salaro, and M. C. Costa, "Polymethylmethacrylate facial implant: a successful personal experience in brazil for more than 9 years," Dermatologic Surgery, vol. 35, no. 8, pp. 1221-1227, 2009.

[16] G. Lemperle, V. Morhenn, and U. Charrier, "Human histology and persistence of various injectable filler substances for soft tissue augmentation," Aesthetic Plastic Surgery, vol. 27, no. 5, pp. 354-366, 2003.

[17] P. J. Guelinckx and N. K. Sinsel, "Facial contour restoration in Barraquer-Simons syndrome using two free anterolateral thigh flaps," Plastic and Reconstructive Surgery, vol. 105, no. 5, pp. 1730-1736, 2000.

[18] J. M. Serra, A. Ballesteros, F. Mesa, A. Bazan, V. Paloma, and J. Sanz, "Use of the temporal muscle flap in Barraquer-Simon's progressive lipodystrophy," Annals of Plastic Surgery, vol. 30, no. 2, pp. 180-182, 1993.

[19] K. Yoshimura, K. Sato, N. Aoi et al., "Cell-assisted lipotransfer for facial lipoatrophy: efficacy of clinical use of adiposederived stem cells," Dermatologic Surgery, vol. 34, no. 9, pp. 1178-1185, 2008.

[20] P. André, "Facial lipoatrophy secondary to a new synthetic filler device (Profill) treated by lipofilling," Journal of cosmetic dermatology, vol. 1, no. 2, pp. 59-61, 2002.

[21] A. Cortese, G. Savastano, and L. Felicetta, "Free fat transplantation for facial tissue augmentation," Journal of Oral and Maxillofacial Surgery, vol. 58, no. 2, pp. 164-169, 2000.

[22] A. Mori, G. Lo Russo, T. Agostini, J. Pattarino, F. Vichi, and M. Dini, "Treatment of human immunodeficiency virusassociated facial lipoatrophy with lipofilling and submalar silicone implants," Journal of Plastic, Reconstructive and Aesthetic Surgery, vol. 59, no. 11, pp. 1209-1216, 2006.

[23] S. R. Coleman, "Structural fat grafts: the ideal filler?" Clinics in Plastic Surgery, vol. 28, no. 1, pp. 111-119, 2001.

[24] C. M. Gleeson, S. Lucas, C. J. Langrish, and R. J. Barlow, "Acute fatal fat tissue embolism after autologous fat transfer in a patient with lupus profundus," Dermatologic Surgery, vol. 37, no. 1, pp. 111-115, 2011.

[25] T. Kamakura and K. Ito, "Autologous cell-enriched fat grafting for breast augmentation," Aesthetic Plastic Surgery, vol. 35, no. 6, pp. 1022-1030, 2011. 


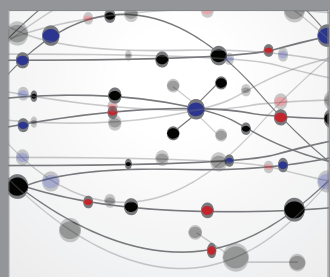

The Scientific World Journal
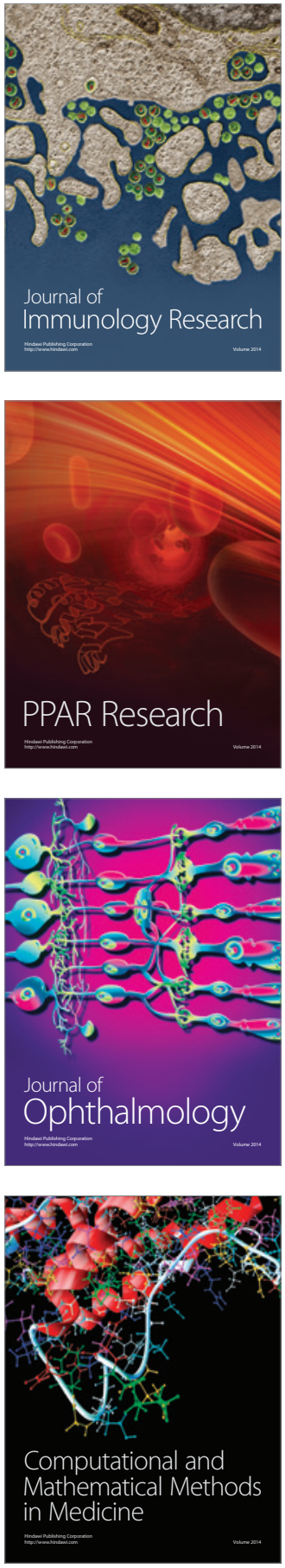

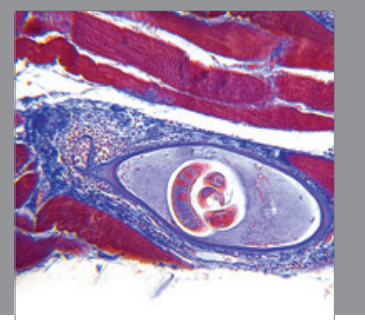

Gastroenterology

Research and Practice
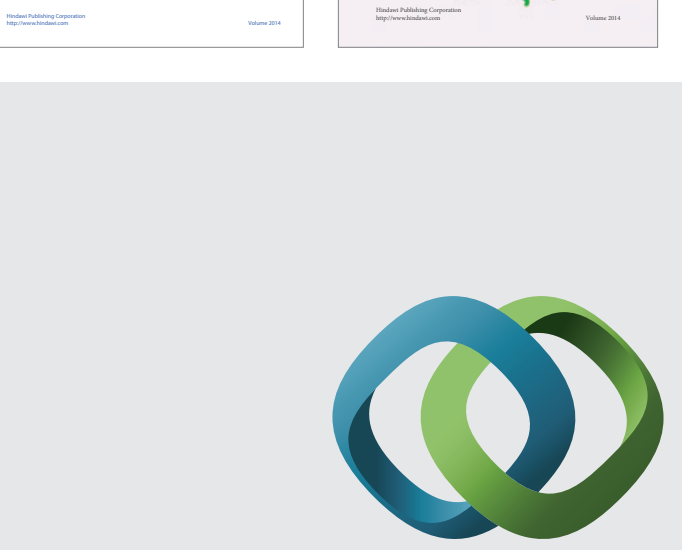

\section{Hindawi}

Submit your manuscripts at

http://www.hindawi.com
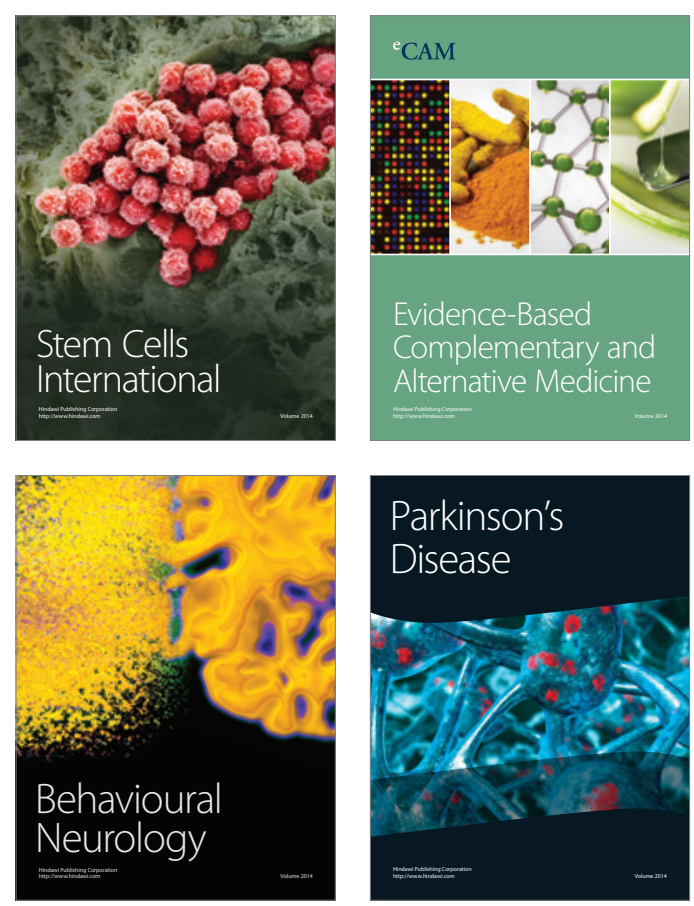

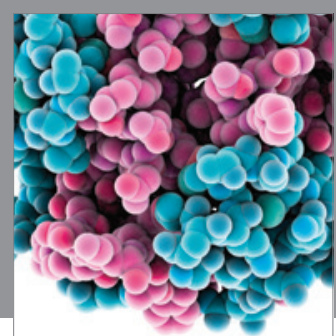

Journal of
Diabetes Research

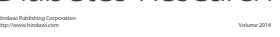

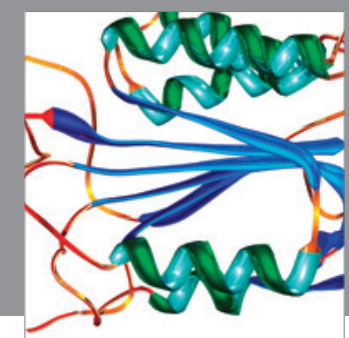

Disease Markers
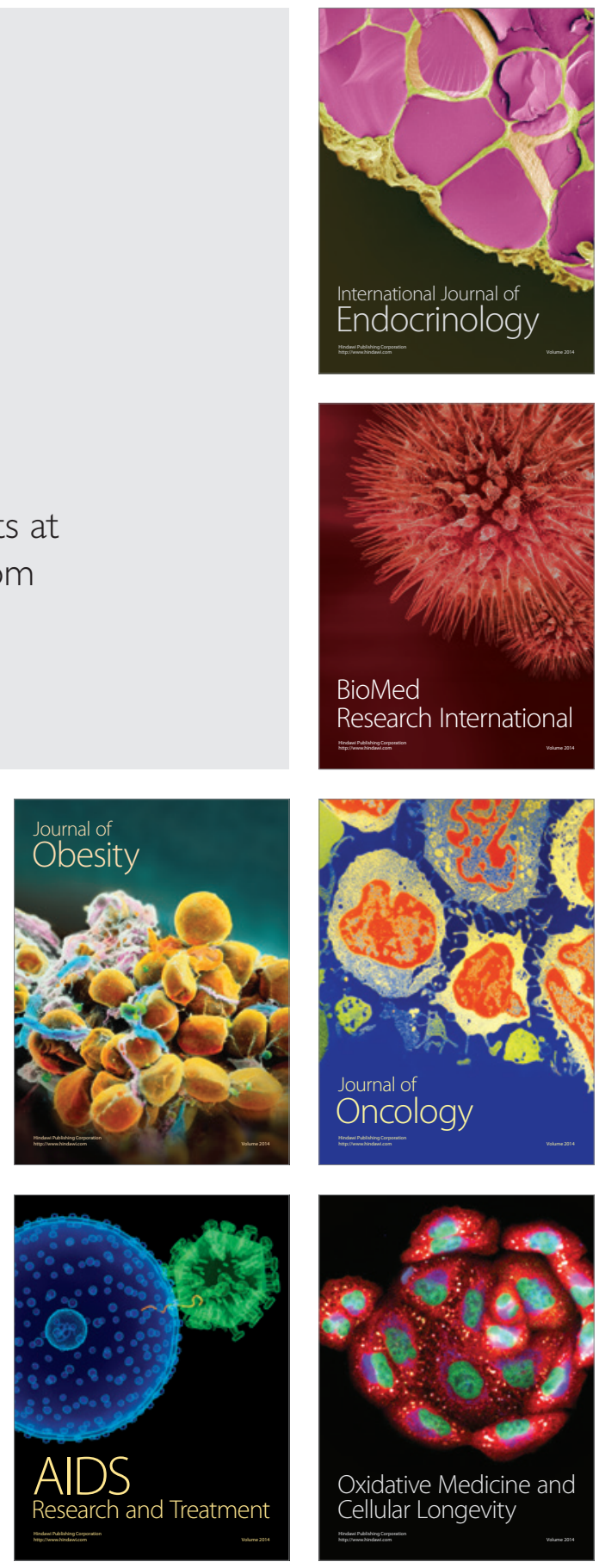